\title{
Effect of Cold Water on Esophageal Motility in Patients With Achalasia and Non-obstructive Dysphagia: A High-resolution Manometry Study
}

\author{
Alessandra Elvevi, ${ }^{1}$ Ivana Bravi, ${ }^{1}$ Aurelio Mauro, ${ }^{1}$ Delia Pugliese, ${ }^{1}$ Andrea Tenca, ${ }^{1}$ Ivan Cortinovis, ${ }^{2}$ Silvano Milani, ${ }^{2}$ Dario Conte \\ and Roberto Penagini ${ }^{1 *}$ \\ ${ }^{1}$ Gastrointestinal Unit 2, Università degli Studi of Milan, Fondazione IRCCS Cà Granda Ospedale Maggiore Policlinico, Milan, Italy; and \\ ${ }^{2}$ Department of Clinical Science and Community Health, Università degli Studi of Milan, Italy
}

\section{Background/Aims}

Swallowing of cold liquids decreases amplitude and velocity of peristalsis in healthy subjects, using standard manometry. Patients with achalasia and non obstructive dysphagia may have degeneration of sensory neural pathways, affecting motor response to cooling. To elucidate this point, we used high-resolution manometry.

\section{Methods}

Fifteen healthy subjects, 15 non-obstructive dysphagia and 15 achalasia patients, after pneumatic dilation, were studied. The 3 groups underwent eight $5 \mathrm{~mL}$ single swallows, two $20 \mathrm{~mL}$ multiple rapid swallows and $50 \mathrm{~mL}$ intraesophageal water infusion $(1 \mathrm{~mL} / \mathrm{sec})$, using both water at room temperature and cold water, in a randomized order.

\section{Results}

In healthy subjects, cold water reduced distal contractile integral in comparison with water at room temperature during single swallows, multiple rapid swallows and intraesophageal infusion (ratio cold/room temperature being 0.67 [95\% Cl, 0.48-0.85], $0.56[95 \% \mathrm{Cl}, 0.19-0.92]$ and $0.24[95 \% \mathrm{Cl}, 0.12-0.37]$, respectively). A similar effect was seen in non-obstructive dysphagia patients $(0.68[95 \% \mathrm{Cl}, 0.51-0.84], 0.69[95 \% \mathrm{Cl}, 0.40-0.97]$ and $0.48[95 \% \mathrm{Cl}, 0.20-0.76]$, respectively), whereas no changes occurred in achalasia patients $(1.06[95 \% \mathrm{Cl}, 0.83-1.29], 1.05[95 \% \mathrm{Cl}, 0.77-1.33]$ and $1.41[95 \% \mathrm{Cl}, 0.84-2.00]$, respectively).

\section{Conclusions}

Our data suggest impairment of esophageal reflexes induced by cold water in patients with achalasia, but not in those with non obstructive dysphagia.

\section{(J Neurogastroenterol Motil 2014;20:79-86)}

\section{Key Words}

Esophageal achalasia; Deglutition disorders; High-resolution manometry

Received: July 24, 2013 Revised: November 4, 2013 Accepted: November 5, 2013

(C) This is an Open Access article distributed under the terms of the Creative Commons Attribution Non-Commercial License (http://creativecommons. org/licenses/by-nc/3.0) which permits unrestricted non-commercial use, distribution, and reproduction in any medium, provided the original work is properly cited.

*Correspondence: Roberto Penagini, MD

Fondazione IRCCS Ca' Granda Ospedale Maggiore Policlinico, Pad. Granelli, via F. Sforza 35, 20122 Milan, Italy

Tel: +39-02-55033595, Fax: +39-02-50320403, E-mail: roberto.penagini@unimi.it

Financial support: None.

Conflicts of interest: None.

Author contributions: Roberto Penagini and Alessandra Elvevi designed the study. Alessandra Elvevi, Aurelio Mauro, Delia Pugliese and Andrea Tenca performed the study. Alessandra Elvevi, Aurelio Mauro, Ivana Bravi and Roberto Penagini analyzed the manometry tracings and performed the analysis. Ivan Cortinovis and Silvano Milani performed the statistical analysis. All authors took part to the discussion of results. Alessandra Elvevi, Ivana Bravi, Roberto Penagini, Ivan Cortinovis and Dario Conte wrote the paper. All authors agreed with the final version of the paper. 


\section{Introduction}

Temperature variations have been shown to modify esophageal motor activity both in man and in the cat. ${ }^{1-6}$ In particular, a few papers performed with standard esophageal manometry reported that in healthy subjects esophageal cooling decreased amplitude and velocity and increased duration of the peristaltic wave, ${ }^{1,25,6}$ whereas one report did not show any effect. ${ }^{7}$ Moreover, Meyer and Castell $^{2}$ have observed that ingestion of 75-100 $\mathrm{mL}$ of a soft ice cream in healthy subjects caused chest pain, associated with dilatation of the esophageal body. Though mechanisms underlying these observations have not been clarified yet, it is presumed that the response is the result of an effect of temperature either on neurotransmitter release ${ }^{8-10}$ or on smooth muscle contractility. ${ }^{11}$

Non-obstructive dysphagia (NOD) is characterized by absence of any endoscopically or radiologically documented esophageal lesion or any motility disorder causing obstruction to bolus transit $^{12}$; pathogenesis of this heterogeneous disorder has not been clarified yet. On the other hand, achalasia results from a well documented degeneration of both intrinsic enteric neural plexus and extrinsic vagal innervations, ${ }^{13}$ and involvement of sensory neural pathways has been recently suggested. ${ }^{14-16}$ Therefore we reasoned that achalasia patients could have an altered motor response to cooling. Furthermore, if esophageal nerves are damaged in NOD patients, their motor response should be altered as well.

Our aim was to evaluate the effects of cold $\left(4^{\circ} \mathrm{C}\right)$ water compared to water at room temperature on esophageal motility in patients with NOD, achalasia and in healthy subjects, using high-resolution manometry (HRM).

\section{Material and Methods}

\section{Study Population}

Fifteen healthy subjects, 5 (33.3\%) men, median age of 29 years (interquartile range [IQR], 25-31), were enrolled as a control group. Fifteen NOD patients, 6 (40\%) men, median age of 61 years (IQR, 51-81), referred to our center for esophageal manometry, were consecutively enrolled, after excluding subjects with systemic diseases which could affect esophageal motility (i.e., diabetes and scleroderma), eosinophylic esophagitis or the following motility disorders, as defined in the Chicago classification $^{17}$ : achalasia, absent peristalsis, esophagogastric junction outflow obstruction, distal esophageal spasm, hypercontractile esophagus and nutcracker esophagus. Finally, 15 patients with achalasia, 8 (53.3\%) men, median age of 62 years (IQR, 53-72) successfully treated with pneumatic dilation and routinely followed-up in our center, were consecutively enrolled.

All patients underwent an X-ray barium swallow and antero-posterior diameter of the esophageal body was similar in achalasia and NOD patients, with median of $2.2 \mathrm{~cm}$ (IQR, 1.6-2.7) vs. median $1.8 \mathrm{~cm}$ (IQR, 1.4-2.0) ( $P=\mathrm{NS})$. No achalasia patient had a diameter of the esophageal body of $>6 \mathrm{~cm}$.

Thirteen achalasia patients had type 2 and 2 had type 1 achalasia at diagnosis, according to the Chicago classification ${ }^{17} ; 12$ NOD patients had weak peristalsis and 3 showed normal peristalsis. In 4 out of 13 type 2 achalasia patients peristaltic motor activity was restored after pneumatic dilation.

Informed consent was obtained from each patient and healthy subject. The study was approved by the Human Research Review Committee of the Fondazione IRCCS Ca'Granda Ospedale Maggiore Policlinico of Milan.

\section{Esophageal Manometry}

HRM (Solar HRM; MMS, Enschede, The Netherlands) was performed using a single-use 20-sensors catheter (MMS G-90500; MMS). The most distal side hole, placed $2 \mathrm{~cm}$ from the tip of the catheter, recorded the intragastric pressure; at $5 \mathrm{~cm}$ more proximally, 5 side holes spaced $1 \mathrm{~cm}$ apart, recorded motor activity of the esophago-gastric junction; the remaining 13 side holes, spaced $2 \mathrm{~cm}$ apart, recorded motor activity of the esophageal body, the upper esophageal sphincter and the pharynx. Catheter lumens were perfused with distilled, degassed water at a rate of $0.1 \mathrm{~mL} / \mathrm{min}$. Each lumen was connected to a pressure transducer (DTX Plus TNF-R; Becton Dickinson, Erembodegem, Belgium). The manometric signals were visualized as isobaric contour plots on a dedicated screen and were stored in a computer using a commercial software (MMS Investigation \& Diagnostic Software Version 8.19 build 2188) for subsequent analysis.

\section{Study Design}

After an overnight fast the esophageal manometry catheter was passed trans-nasally under topical anaesthesia (Lidocaine spray $10 \%$ ). The catheter was positioned so that side holes spaced $1 \mathrm{~cm}$ apart straddled the lower esophageal sphincter (LES). The test was performed in the recumbent right-sided position. A second catheter (10 F, Gastric Sump Tube; Medovations, Milwaukee, WI, USA) was inserted and the tip positioned at $30 \mathrm{~cm}$ from 
the nares, in order to perform aspiration both after intubation and at predetermined intervals (see below), and to infuse water.

As detailed in Figure 1, each subject was tested at room temperature and cold $\left(4^{\circ} \mathrm{C}\right)$ water in a randomized order with the 2 experimental condition being separated by 15 minutes in order to allow recovery of physiological esophageal temperature. Water temperature was monitored with a dedicated thermometer located inside the water's jar. Both with water at room-temperature and cold water, subjects first underwent a series of eight $5 \mathrm{~mL}$ single swallows (SS) and 2 multiple rapid swallows (MRS) of $20 \mathrm{~mL}$ each (20 mL MRS), within 10 seconds, ${ }^{18}$ each separated by 20-30 seconds; SS and MRS were followed by esophageal aspiration in order to keep intraesophageal pressure negative. Afterwards, esophageal motility was recorded for 30 seconds as baseline period followed by infusion of $50 \mathrm{~mL}$ of water into the esophagus at a rate of $1 \mathrm{~mL} / \mathrm{sec}$ through the second catheter, asking subjects to avoid swallowing. Finally, in healthy subjects only, the esophagus was exposed to a stronger cooling stimulus with multiple rapid swallowing of $200 \mathrm{~mL}$ within 30 seconds (200 mL MRS). ${ }^{19}$

Along the whole study period, patients and subjects were encouraged to report their symptoms of chest pain and dysphagia by raising their hands.

\section{Data Analysis}

\section{Esophageal pressure waves and lower esophageal sphincter relaxation after water swallowing}

Distal contractile integral (DCI) and contractile front veloc-

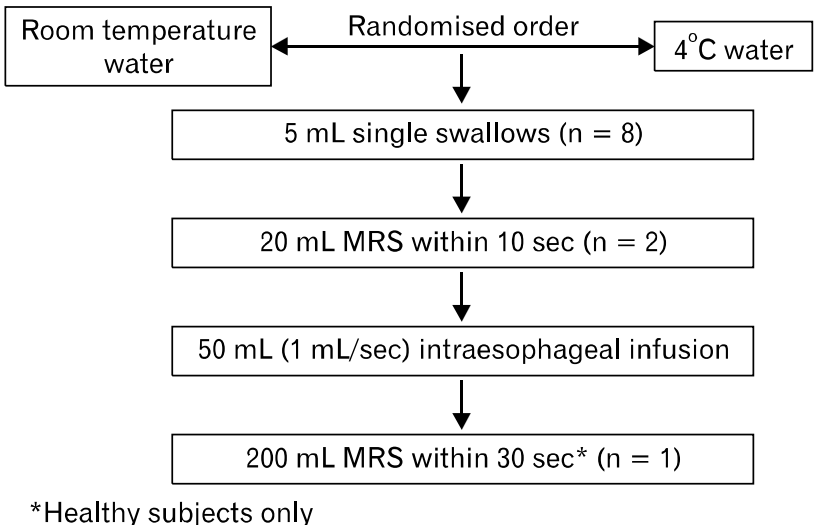

Figure 1. Study protocol. All subjects and patients performed 8 single swallows, 2 multiple rapid swallows (MRS) and 1 intraesophageal slow infusion of $50 \mathrm{~mL}$ of water, with both cold and room temperature water, administered in randomized order. Furthermore, healthy subjects underwent $200 \mathrm{~mL}$ MRS. ity (CFV) for SS were registered. LES relaxation was evaluated by measuring 4-second integrated relaxation pressure (4s IRP). The same classification and variables (DCI, CFV, 4s IRP and maximal pressure) were used to characterize the motor response to $20 \mathrm{~mL}$ MRS.

MRS (healthy subjects only) of $200 \mathrm{~mL}$ was evaluated similarly to SS and $20 \mathrm{~mL} \mathrm{MRS}$ and additionally, gastroesophageal pressure gradient of the last 5 seconds of MRS was measured at 3 $\mathrm{cm}$ above the LES. CFV was calculated only in those patients and subjects with peristalsis in whom contractile deceleration point was measurable.

In patients with achalasia having panesophageal pressurization in response to swallowing $(\mathrm{n}=9)$, maximal pressure observed in the distal segment was also evaluated, according to Pandolfino et $\mathrm{al}^{20}$ as a further index of contractility after swallows. Briefly, maximal pressure was calculated by scrolling up the isobaric contour tool to the pressure value at which no isobaric area was identified within the distal esophageal segment.

Ratios between values during cold water and during room temperature water were calculated for each variable.

Percentage of failed peristalsis/subject, i.e., minimal $(<3$ $\mathrm{cm}$ ) integrity of the $20 \mathrm{mmHg}$ isobaric contour distal to the proximal pressure trough, ${ }^{17}$ occurring after SS, $20 \mathrm{~mL} \mathrm{MRS}$ and 200 $\mathrm{mL}$ MRS was also calculated.

\section{Intraesophageal water infusion}

Spontaneous motor response of the esophageal body during water infusion was evaluated by measuring cumulative motor activity, excluding motor response due to involuntary swallowing. This index was named as 1-minute DCI. The effect of cold water was quantified with the ratio between 1-minute DCI obtained with cold water and the one obtained with room temperature water.

\section{Statistical Methods}

Median and interquartile range of esophageal motility indexes (DCI, 1-minute DCI, CFV, 4s IRP and maximal distal intraesophageal pressure) after SS, MRS and infusion of cold or room temperature water were computed for each group of patients. Ratios (cold/room temperature) of the various motility indexes were compared among groups using univariate (ANOVA) and multivariate (MANOVA) linear models, before and after log and rank transformation, resorting to GLM procedure of SAS statistical package. Group (healthy, NOD and achalasia) was independent variable while the type of stimulus (SS, MRS and in- 
Table 1. Esophageal Motility Variables in the 3 Groups, Expressed as Median, Interquartile Range, Both With Water at Room Temperature and Cold Water

\begin{tabular}{|c|c|c|c|c|c|c|c|}
\hline & & \multicolumn{2}{|c|}{ Healthy } & \multicolumn{2}{|c|}{ NOD } & \multicolumn{2}{|c|}{ Achalasia } \\
\hline & & Room T & Cold & Room T & Cold & Room T & Cold \\
\hline \multirow[t]{3}{*}{ SS } & DCI & $\begin{array}{c}980 \\
(570-1,552)\end{array}$ & $\begin{array}{c}627 \\
(264-1,214)\end{array}$ & $\begin{array}{c}1,903 \\
(1,137-3,706)\end{array}$ & $\begin{array}{c}1,256 \\
(889-2,414)\end{array}$ & $\begin{array}{c}676 \\
(301-1,331)\end{array}$ & $\begin{array}{c}709 \\
(209-1,098)\end{array}$ \\
\hline & $\mathrm{CFV}^{\mathrm{a}}$ & $\begin{array}{c}3.1 \\
(2.6-3.3)\end{array}$ & $\begin{array}{c}2.5 \\
(2.2-3.2)\end{array}$ & $\begin{array}{c}2.8 \\
(2.6-3.3)\end{array}$ & $\begin{array}{c}2.8 \\
(2.5-3.1)\end{array}$ & $\begin{array}{c}3.9 \\
(3.4-5.6)\end{array}$ & $\begin{array}{c}6.3 \\
(4.3-8.2)\end{array}$ \\
\hline & $4 s$ IRP & $\begin{array}{c}2 \\
(0.6-2.9)\end{array}$ & $\begin{array}{c}1.8 \\
(0.5-2.9)\end{array}$ & $\begin{array}{c}2.6 \\
(0.9-5.1)\end{array}$ & $\begin{array}{c}0.8 \\
(0.1-2.9)\end{array}$ & $\begin{array}{c}3.1 \\
(1.2-6.5)\end{array}$ & $\begin{array}{c}3.1 \\
(2.1-5.6)\end{array}$ \\
\hline \multirow[t]{3}{*}{$20 \mathrm{~mL}$ MRS } & DCI & $\begin{array}{c}1,421 \\
(1,051-2,960)\end{array}$ & $\begin{array}{c}824 \\
(285-961)\end{array}$ & $\begin{array}{c}1,821 \\
(1,409-4,671)\end{array}$ & $\begin{array}{c}1,220 \\
(584-2,452)\end{array}$ & $\begin{array}{c}695 \\
(532-1,250)\end{array}$ & $\begin{array}{c}790 \\
(469-1,351)\end{array}$ \\
\hline & $\mathrm{CFV}^{\mathrm{a}}$ & $\begin{array}{c}2.7 \\
(2.2-3.0)\end{array}$ & $\begin{array}{c}2.2 \\
(1.5-2.6)\end{array}$ & $\begin{array}{c}3.2 \\
(2.7-3.6)\end{array}$ & $\begin{array}{c}2.4 \\
(2.0-2.7)\end{array}$ & $\begin{array}{c}3.1 \\
(1.8-4.7)\end{array}$ & $\begin{array}{c}3.9 \\
(2.7-5.5)\end{array}$ \\
\hline & $4 s$ IRP & $\begin{array}{c}1.6 \\
(0.4-2.4)\end{array}$ & $\begin{array}{c}1.5 \\
(0.3-1.9)\end{array}$ & $\begin{array}{c}0.7 \\
(0.2-3)\end{array}$ & $\begin{array}{c}2 \\
(0.1-3.8)\end{array}$ & $\begin{array}{c}2.3 \\
(0.4-7.3)\end{array}$ & $\begin{array}{c}2.7 \\
(0.7-8)\end{array}$ \\
\hline Infusion & 1-minute $\mathrm{DCI}^{\mathrm{b}}$ & $\begin{array}{c}1,772 \\
(546-3,153)\end{array}$ & $\begin{array}{c}269 \\
(26-682)\end{array}$ & $\begin{array}{c}3,415 \\
(1,540-6,233)\end{array}$ & $\begin{array}{c}1,474 \\
(289-2,445)\end{array}$ & $\begin{array}{c}1,625 \\
(392-4,264)\end{array}$ & $\begin{array}{c}1,358 \\
(793-3,906)\end{array}$ \\
\hline
\end{tabular}

${ }^{a}$ In achalasia and non-obstructive dysphagia (NOD) patients contractile front velocity (CFV) was measured in those who showed peristalsis and an identifiable contractile deceleration point, i.e., 4 achalasia, 8 (single swallow [SS]) and 6 (multiple rapid swallows [MRS]) NOD patients; ${ }^{\text {b }}$-minute distal contractile integral [DCI], 1-minute cumulative DCI was calculated during intraesophageal water infusion as a measure of spontaneous esophageal activity.

4s IRP, 4-second integrated relaxation pressure.

fusion) was dependent variable.

\section{Results}

All patients and healthy subjects completed the study protocol. Healthy controls had different mean age $(P<0.05)$ from NOD and achalasia patients who shared similar mean age. The 3 groups did not differ in gender composition. None of the subjects studied reported symptoms during the protocol. The basal intraesophageal pressure was negative in the 3 groups, the values being median $-4 \mathrm{mmHg}$ (IQR, -6 to -3 ), median $-4.5 \mathrm{mmHg}$, (IQR, -6 to -4 ) and median $-4.5 \mathrm{mmHg}$ (IQR, -7 to -3 ) in healthy subject, NOD and achalasia patients, respectively. DCI, $\mathrm{CFV}$ and $4 \mathrm{~s}$ IRP during SS and $20 \mathrm{~mL}$ MRS and 1-minute DCI during water infusion, in both experimental condition, are shown in Table 1.

\section{Effect of Cold Water: Comparison Within Each Group}

\section{Healthy subjects}

Compared to room temperature water, cold water significantly reduced DCI after SS and MRS and 1-minute DCI during infusion. The ratios of cold water/room temperature water

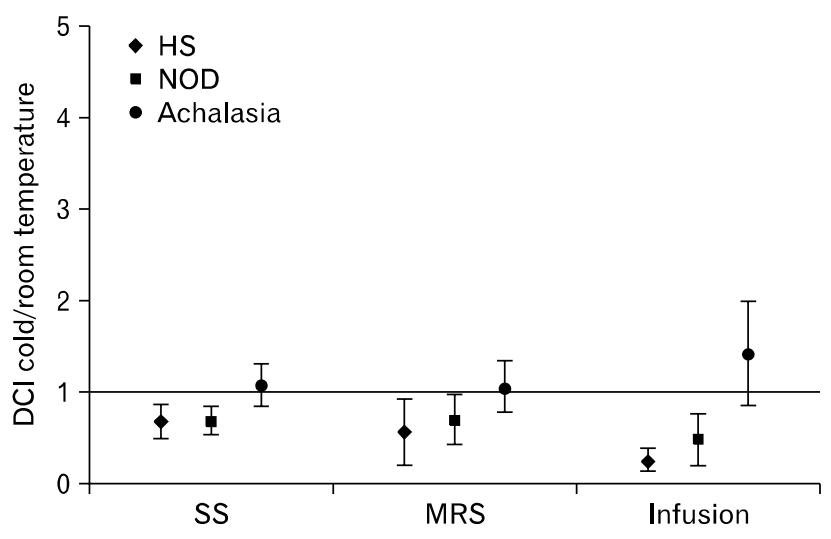

Figure 2. Effect of cold water on distal contractile integral (DCI) for single swallow (SS) and $20 \mathrm{~mL}$ multiple rapid swallows (MRS), and on 1-minute DCI for $50 \mathrm{~mL}$ water infusion in healthy subjects (HS), non-obstructive dysphagia (NOD) and achalasia patients. Data are expressed as ratio between DCI after cold water and DCI after room temperature water. Median and interquartile range are shown.

were 0.67 (95\% CI, 0.48-0.85), 0.56 (95\% CI, 0.19-0.92) and 0.24 (95\% CI, 0.12-0.37), respectively (Fig. 2). The effect was consistent, occurring in 13/15 subjects after both SS and $20 \mathrm{~mL}$ MRS and in all subjects during infusion.

Moreover, cold water reduced CFV both after SS and MRS compared to room temperature water, although the effect was less 


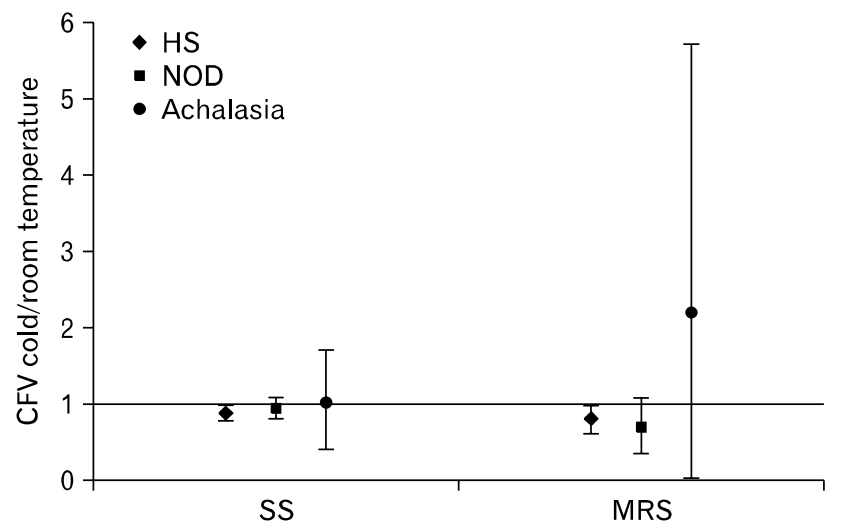

Figure 3. Effect of cold water on contractile front velocity (CFV) for single swallow (SS) and $20 \mathrm{~mL}$ multiple rapid swallows (MRS) in healthy subjects (HS), non-obstructive dysphagia (NOD) ( $\mathrm{n}=8$ after SS and $n=6$ after MRS) and achalasia patients $(n=4)$. Data are expressed as ratio between $\mathrm{CFV}$ after cold water and $\mathrm{CFV}$ after room temperature water. Median and interquartile range are shown.

marked than for DCI, the ratios being 0.87 (95\% CI, 0.77-0.98) and 0.79 (95\% CI, 0.59-0.99), respectively (Fig. 3). Conversely, cold water had no effect on 4s IRP both after SS and MRS, the ratios being 1.5 (95\% CI, 0.45-2.55) and 1.4 (95\% CI, 1.053.85), respectively (Fig. 4).

Regarding $200 \mathrm{~mL}$ MRS, cold water did not affect intraesophageal pressure in the last 5 seconds of MRS, the ratio being 1.04 (95\% CI, 0.12-1.95). On the other hand, the effect was marked with after-contraction, 10 subjects having an after contraction with room temperature water and none with cold water.

Interestingly, the failed peristalsis after 3 swallowing exercises in our data suggests an increasing impairment of peristalsis as the volume of cold water increases. Overall percentage of events with failed peristalsis attributed to cold water increased from $13 \%$ for $5 \mathrm{~mL} \mathrm{SS}$ to $33 \%$ for $20 \mathrm{~mL} \mathrm{MRS} \mathrm{and} \mathrm{up} \mathrm{to} 67 \%$ for $200 \mathrm{~mL}$ MRS.

\section{NOD patients}

Compared with room temperature water, cold water significantly reduced DCI after SS (0.68 [95\% CI, 0.51-0.84]), MRS (0.69 [95\% CI, 0.40-0.97]) and 1-minute DCI during water infusion (0.48 [95\% CI, 0.20-0.76]) (Fig. 2). The effect was consistent also in this group, occurring in $12 / 15$ patients after $\mathrm{SS}$ and $20 \mathrm{~mL} \mathrm{MRS}$ and in 14/15 during infusion.

Contractile deceleration point was clearly identifiable and consequently CFV was assessed in 12 (SS) and 10 (MRS) patients with room temperature water, and 8 (SS) and 6 (MRS) patients with cold water. No effect of cold water was noted on CFV

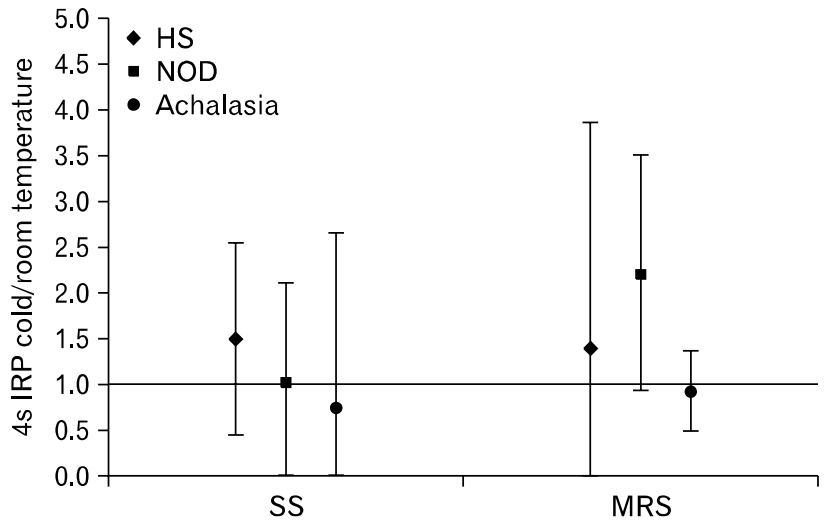

Figure 4. Effect of cold water on 4-second integrated relaxation pressure (4s IRP) for single swallow (SS) and $20 \mathrm{~mL}$ multiple rapid swallows (MRS) in healthy subjects (HS), non-obstructive dysphagia (NOD) and achalasia patients. Data are expressed as ratio between 4 s IRP after cold water and $4 \mathrm{~s}$ IRP after room temperature water. Median and interquartile range are shown.

and 4s IRP (Fig. 3 and 4).

\section{Achalasia patients}

Compared to room temperature water, cold water had no effect on DCI after SS (1.06 [95\% CI, 0.83-1.29]), 20 mL MRS (1.05 [95\% CI, 0.77-1.33]) and 1-minute DCI during water infusion (1.41 [95\% CI, 0.84-2.00]) (Fig. 2). Motor response in the esophageal body after swallows was also analyzed separately for patients with panesophageal pressurization $(n=9)$ and those with peristalsis $(n=4)$. In the first group maximal esophageal pressure in the distal esophagus was not modified by cold water both after SS (1.14 [95\% CI, 0.80-1.40]) and $20 \mathrm{~mL}$ MRS ( 0.80 [95\% CI, 0.50-1.15]). In the second group, DCI was unchanged by cold water both after SS (1.10 [95\% CI, 0.50-1.70]) and $20 \mathrm{~mL}$ MRS (1.00 [95\% CI, 0.50-1.50]).

Similarly to DCI, cold water had no effect on CFV in patients with peristalsis and on $4 \mathrm{~s}$ IRP in the whole group, when compared to room temperature water (Fig. 3 and 4).

\section{Effect of Cold Water: Comparison Among Groups}

This analysis is shown in Table 2. Cold water induced a DCI decrease during SS, and MRS while 1-minute DCI decrease during infusion, which was significantly larger in healthy subjects and NOD patients than in achalasia patients whereas no difference was found between healthy subjects and NOD patients. Analogous results were obtained when the responses to SS, MRS and infusion of cold water were simultaneously analyzed with a 
Table 2. Effect of Cold Water: Comparison Among Groups

\begin{tabular}{llccccccc}
\hline & \multicolumn{3}{c}{ Effect of cold water } & \multicolumn{2}{c}{ Wilks' lambda } & \multicolumn{2}{c}{ Contrasts (Wilks' lambda) } \\
\cline { 3 - 4 } & & Healthy (A) & NOD (B) & Achalasia (C) & (model) & A vs. C & A vs. B & B vs. C \\
\hline \multirow{2}{*}{ DCI } & SS & $P=0.007$ & $P=0.001$ & $P=0.734$ & $P=0.008$ & $P=0.003$ & $P=0.634$ & $P=0.010$ \\
& MRS & $P=0.002$ & $P=0.007$ & $P=0.972$ & & & \\
& Infusion & $P<0.0001$ & $P=0.001$ & $P=0.578$ & & & \\
CFV & SS & $P=0.605$ & $P=0.860$ & $P=0.178$ & $P=0.139$ & $P=0.0667$ & $P=0.385$ & $P=0.144$ \\
& MRS & $P=0.261$ & $P=0.056$ & $P=0.419$ & & & \\
4s IRP & SS & $P=0.989$ & $P=0.071$ & $P=0.297$ & $P=0.345$ & $P=0.635$ & $P=0.122$ & $P=0.439$ \\
& MRS & $P=0.835$ & $P=0.022$ & $P=0.529$ & & & & \\
\hline
\end{tabular}

NOD, non-obstructive dysphagia; DCI, distal contractile integral; CFV, contractile front velocity; 4s IRP, 4-second integrated relaxation pressure.

MANOVA model $(P=0.008)$.

On the other hand, cold water did not induce any significant difference between groups in CFV and 4s IRP, as emerged from both the univariate and multivariate analysis (CFV: $P=0.139$ and 4s IRP: $P=0.345$ ).

\section{Discussion}

Aim of our study was to evaluate the effects of esophageal cooling on motility of the esophagus in patients with NOD and achalasia compared to healthy subjects. Our major findings were that cold water reduced strength of the peristaltic wave in healthy subjects and NOD patients, whereas it had no effect on achalasia patients.

To our knowledge, this is the first study evaluating the effect of temperature on esophageal motility in patients with NOD and achalasia patients after successful pneumatic dilation. A small study ${ }^{21}$ was recently published on the effect of cold water in 12 untreated achalasia patients, suggesting an increased duration of pressure activity in the esophageal body.

However results of this study should be viewed with caution because of the limitations in study design. Cold water was administered after room temperature water, i.e., without randomization, and no aspiration was applied in a group of untreated patients, who are known to have esophageal stasis. This raises the concern for sequential effect, i.e., that progressive accumulation of swallowed water and air in the esophagus had stimulated motility. Previous studies had already explored the effect of swallow-induced motility on healthy subjects using standard manometry. ${ }^{1,2,5,6}$ Findings were controversial, some showing reduced amplitude and velocity of the peristaltic wave ${ }^{1,2,5}$ and others no effect. ${ }^{6}$ Our report confirms a definite effect on peristalsis. We have expanded observations in healthy subjects by evaluating spontaneous motor activity induced by intraesophageal water infusion. The effect of cooling was similar to the one observed in primary peristalsis both in healthy subjects and the 2 patients groups, suggesting that the underlying mechanism of cooling is predominantly within the esophagus itself, although at present it has not been clarified yet. Previous studies on extraesophageal muscle tissue have suggested that it could be the result of an effect of temperature on neurotransmitter release ${ }^{8-10}$ or on smooth muscle contractility. ${ }^{11}$ Moreover, esophageal thermoreceptors, which have been documented in the lower thoracic esophagus of the cat, ${ }^{4}$ could play a role. It is interesting to note that, in the study conducted with the isolated cat esophagus, cold stimulations increased esophageal contractions, ${ }^{4}$ while in our experiments cold water reduced pressure waves amplitude in healthy subjects and NOD patients. The difference in response could be due either to the different experimental condition, i.e., "ex vivo" vs. "in vivo," or to the different species.

Differently from the esophageal body, LES motor function was not affected by cooling in all the 3 groups of subjects, in line with previous studies conducted in healthy subjects using standard manometry. ${ }^{1,5,6}$ This could be explained by experimental data from De Carle et al, ${ }^{22}$ showing that the LES is much less temperature sensitive than the esophageal body.

With regards to NOD patients, they are a heterogeneous group and variable damages in both inhibitory and excitatory neural pathways have been hypothesized. We have included only NOD patients with normal or weak peristalsis according to the Chicago classification, thus excluding patients with an hypercontractile disorder in order to decrease pathophysiological heterogeneity. Previous studies have suggested that, in NOD patients with ineffective motility, neuromuscular structures are at least partially preserved and the main nerve damage is at the neural cholinergic stimulation level. ${ }^{23,24}$ Our observations that NOD 
patients both with weak and normal peristalsis showed a consistent DCI reduction after cold water, which was similar to the one observed in healthy subjects, are in line with this hypothesis. Differently from healthy subjects, cold water did not affect velocity of peristalsis. This difference should be viewed with caution because, on one side, the effect of cold water on CFV was modest in healthy subjects and on the other, only half of the NOD patients were evaluated. Whether NOD patients with hypercontractile disorders, who may have an alteration of inhibitory neural pathways, retain the ability to decrease their DCI with cooling remains to be determined.

With regards to achalasia patients, esophageal cooling did not affect motor activity also in the subgroup where peristaltic activity was present. Achalasia is a primary motility disorder characterized by impairment of inhibitory neural pathways due to degeneration of inhibitory ganglion cells in the myenteric plexus of the esophagus and degenerative lesions in the vagal nerves and the dorsal motor nucleus. ${ }^{13,25-28}$ Nerve damage is probably heterogeneous, as suggested by motor response to MRS. ${ }^{18}$ The likely explanation for the lack of effect of cooling in achalasia is abolition of temperature induced neural reflexes because of the severe neural damage. In particular the neurodegenerative process could involve sensory neural pathways, which have been little explored in achalasia. Some uncontrolled data and controlled experimental data looking at mechanosensitivity using a barostat, at chemosensitivity using a modified Bernsten test and at the response to esophageal electrical stimulation have suggested that achalasia patients have a disordered visceral perception. ${ }^{14,15}$

Two theoretical concerns regarding our finding in achalasia patients should be mentioned. First of all it could be argued that panesophageal pressurization in response to water swallowing, present in the majority of our patients, represents a cavity pressure wave rather than a true contraction as detected in patients with peristalsis. Although this is true, previous convincing findings with the use of high-frequency intraluminal ultrasonography have shown that panesophageal pressurization is the result of longitudinal muscle contraction. ${ }^{29}$ Nevertheless we have added measurement of a simple index related to esophageal wall contraction, i.e. maximal distal intraesophageal pressurization, which has confirmed no effect of cooling in these achalasia patients. The second concern relates to the fact that the esophagus of achalasia patients may be more dilated than the one of NOD patients or healthy subjects and therefore could need more volume of water to get cool. In order to avoid this bias, we recruited only patients successfully treated with pneumatic dilatation in whom the esoph- ageal body was not dilated and checked that the esophagus was empty by aspirating at predetermined intervals during the study.

A final consideration needs to be done on the amount of esophageal cooling. Intraluminal temperature was not measured during the experiment, however previous studies have shown that intraesophageal temperature decreased immediately after the first cold water swallow and remained stable during the whole cooling stimulus. ${ }^{6}$ Healthy subjects have been shown to develop chest pain associated with esophageal dilatation and absence of esophageal peristalsis during rapid ice cream ingestion ${ }^{2}$ and occasionally patients with dysphagia report exacerbation of symptoms during swallowing of cold food. During our experiments no one complained of dysphagia or chest pain. It is possible that stronger cooling stimuli are needed in order to induce symptoms with more severe impairment of esophageal motility. In this respect it is interesting to note that in our study impairment of swallow-induced peristalsis increased as the volume of cold water did.

In conclusion, our data have expanded observations in healthy humans, showing that cooling induces inhibition of both primary peristalsis and spontaneous motor activity, presumably as result of a neural reflex. Furthermore they have shown impairment of cold induced motor inhibition in achalasia, but not in NOD patients with normal or hypotensive motility.

\section{References}

1. Winship DH, Viegas de Andrade SR, Zboralske FF. Influence of bolus temperature on human esophageal motor function. J Clin Invest 1970;49:243-250

2. Meyer GW, Castell DO. Human esophageal response during chest pain induced by swallowing cold liquids. JAMA 1981;246:20572059.

3. Ott DJ, Kelly RJ, Gelfand DW. Radiographic effects of cold barium suspensions on esophageal motility. Radiology 1981;140:830-833.

4. El Quazzani T, Mei N. Electrophysiologic properties and role of the vagal thermoreceptors of lower esophagus and stomach of cat. Gastroenterology 1982;83:995-1001.

5. Kaye MD, Kilby AE, Harper PC. Changes in distal esophageal function in response to cooling. Dig Dis Sci 1987;32:22-27.

6. Ozdogan O, Saadalla AJ, Emironal G, Yeğen BC, Ulusoy NB. Effect of intraluminal temperature on human oesophageal motor function. Clin Physiol 1998;18:504-509.

7. Dooley CP, Di Lorenzo C, Valenzuela JE. Esophageal function in humans. Effects of bolus consistency and temperature. Dig Dis Sci 1990;35:167-172.

8. Kuriyama $\mathrm{H}$. The effect of temperature on neuromuscular transmission in the vas deferens of The guinea-pig. J Physiol 1964;170: 561-570.

9. Hubbard JI, Jones SF, Landau EM. The effect of temperature 
change upon transmitter release, facilitation and post-tetanic potentiation. J Physiol 1971;216:591-609.

10. Jager LP, Den Hertog AD. Effect of temperature on the transmitter release from the "purinergic" nerves in the guinea-pig taenia coli. Eur J Pharmacol 1974;29:201-205.

11. Wiederhielm CA. Effects of temperature and transmural pressure on contractile activity of vascular smooth muscle. Bibl Anat 1967;9: 321-327.

12. Chen CL, Szczesniak MM, Cook IJ. Identification of impaired oesophageal bolus transit and clearance by secondary peristalsis in patients with non-obstructive dysphagia. Neurogastroenterol Motil 2008;20:980-988.

13. Francis DL, Katzka DA. Achalasia: update on the disease and its treatment. Gastroenterology 2010;139:369-374.

14. Rate AJ, Hobson AR, Barlow J, Bancewicz J. Abnormal neurophysiology in patients with oesophageal motility disorders. Br J Surg 1999;86:1202-1206.

15. Brackbill S, Shi G, Hirano I. Diminished mechanosensitivity and chemosensitivity in patients with achalasia. Am J Physiol Gastrointest Liver Physiol 2003;285:G1198-G1203.

16. Ponce J, Ortiz V, Maroto N, Ponce M, Bustamante M, Garrigues $\mathrm{V}$. High prevalence of heartburn and low acid sensitivity in patients with idiopathic achalasia. Dig Dis Sci 2011;56:773-776.

17. Bredenoord AJ, Fox M, Kahrilas PJ, et al. Chicago classification criteria of esophageal motility disorders defined in high resolution esophageal pressure topography. Neurogastroenterol Motil 2012; 24(suppl 1):57-65.

18. Savojardo D, Mangano M, Cantù P, Penagini R. Multiple rapid swallowing in idiopathic achalasia: evidence for patients' heterogeneity. Neurogastroenterol Motil 2007;19:263-269.

19. Daum C, Sweis R, Kaufman E, et al. Failure to respond to physiologic challenge characterizes esophageal motility in erosive gastro-esophageal reflux disease. Neurogastroenterol Motil 2011;23:
517, e200.

20. Pandolfino JE, Kwiatek MA, Nealis T, Bulsiewicz W, Post J, Kahrilas PJ. Achalasia: a new clinically relevant classification by high-resolution manometry. Gastroenterology 2008;135:1526-1533.

21. Ren Y, Ke M, Fang X, et al. Response of esophagus to high and low temperatures in patients with achalasia. J Neurogastroenterol Motil 2012;18:391-398.

22. De Carle DJ, Szabo AC, Christensen J. Temperature dependence of responses of esophageal smooth muscle to electrical field stimulation. Am J Physiol 1977;232:E432-E436.

23. Fornari F, Blondeau K, Durand L, et al. Relevance of mild ineffective oesophageal motility (IOM) and potential pharmacological reversibility of severe IOM in patients with gastro-oesophageal reflux disease. Aliment Pharmacol Ther 2007;26:1345-1354.

24. Fornari F, Bravi I, Penagini R, Tack J, Sifrim D. Multiple rapid swallowing: a complementary test during standard oesophageal manometry. Neurogastroenterol Motil 2009;21:718, e41.

25. Adams CW, Brain RH, Trounce JR. Ganglion cells in achalasia of the cardia. Virchows Arch A Pathol Anat Histol 1976;372:75-79.

26. Aggestrup S, Uddman R, Sundler F, et al. Lack of vasoactive intestinal polypeptide nerves in esophageal achalasia. Gastroenterology 1983;84(5 Pt 1):924-927.

27. Penagini R, Bartesaghi B, Zannini P, Negri G, Bianchi PA. Lower oesophageal sphincter hypersensitivity to opioid receptor stimulation in patients with idiopathic achalasia. Gut 1993;34:16-20.

28. De Giorgio R, Di Simone MP, Stanghellini V, et al. Esophageal and gastric nitric oxide synthesizing innervation in primary achalasia. Am J Gastroenterol 1999;94:2357-2362.

29. Hong SJ, Bhargava V, Jiang Y, Denboer D, Mittal RK. A unique esophageal motor pattern that involves longitudinal muscles is responsible for emptying in achalasia esophagus. Gastroenterology 2010;139:102-111. 